\title{
Gender disparity in authorships of manuscripts on the COVID-19 outbreak
}

\author{
Cristina Bittante ${ }^{1} \cdot$ Giorgia Beatrice $^{1} \cdot$ Lorenza Carletti $^{1} \cdot$ Alessandro Mantovani $^{1}$ (D)
}

Received: 27 April 2020 / Accepted: 16 May 2020 / Published online: 5 June 2020

(C) Springer-Verlag GmbH Germany, part of Springer Nature 2020

In a recent manuscript regarding the gendered impacts of the COVID-19 outbreak, Wenham et al. (2020) called the governments and global health institutions of different countries to take some important actions. First, as specified by these authors, the governments and global health institutions should consider the sex and gender effects of the COVID-19 outbreak (Wenham et al. 2020). Second, the governments and global health institutions should also conduct an analysis of the gendered impacts of the multiple outbreaks (Wenham et al. 2020). Lastly, they should incorporate the voices of women on the front line of the response to COVID-19 (Wenham et al. 2020). Over the last four months, many different types of manuscripts regarding specific aspects of the COVID-19 outbreak have been published in PubMed and a lot of journals have called works regarding this issue with "fast track decision". Given that, in science, gender disparity is an important and recognized issue (Schwalbe and Fearon 2018; Mathad et al. 2019; Shannon et al. 2019) (for instance, the United Nations Educational, Scientific and Cultural Organization's Women in Science data has recently demonstrated that $\sim 30 \%$ of the world's researchers were women in 2018 [Mathad et al. 2019]), we have assessed the percentages of female first and last authors among all manuscripts on the COVID-19 outbreak available so far. Searching in PubMed (which has a specific section on COVID-19) from January 1st, 2020 to March 24th, 2020, we obtained 1448 items (namely, manuscripts).

Alessandro Mantovani

alessandro.mantovani@univr.it

1 Section of Endocrinology, Diabetes and Metabolism, University and Azienda Ospedaliera Universitaria Integrata of Verona, Piazzale Stefani, 1, 37126 Verona, Italy
We extracted information on the names of the first and last authors in order to find if they were men or women (by photos, information on ResearchGate or other websites), as well as information on journals. Of the initial 1448 items, we excluded 312, as we were unable to obtain the gender of the first and/or last authors exactly. Hence, after this selection, the number of items included in the final statistical analysis was 1136 . Table 1 summarizes the percentage of female researchers among the first and last authors in all manuscripts on COVID-19 published up till March 24th, 2020. As reported, we found that $26.5 \%$ (95\% confidence interval $23.9-29.2 \%$ ) of first authors were female researchers and $25.3 \%$ (95\% confidence interval 22.3 $28.4 \%$ ) of last authors were women. No significant difference was observed when we stratified the manuscripts by journal rank (namely, impact factor $<10$ vs. impact factor $\geq 10$ ) or journal country.

In a period characterized by the COVID-19 outbreak and a "fast track" for the publication of manuscripts regarding this severe problem, it again emerges that female researchers tend to publish much fewer manuscripts than men and that they are much less represented in the relevant positions of manuscript authorships. In this context, it is important to note that, to date, roughly $75 \%$ of trainees, health workers, and faculty involved in global health are women (Mathad et al. 2019). Although this is a novel topic that is affecting the whole world, the gap in gender authorships is still evident in science. 
Table 1 Percentage of female researchers among the first and last authors of the manuscripts on COVID-19 published up till March 24th, 2020

\begin{tabular}{|c|c|c|c|c|}
\hline & $\begin{array}{l}\text { Percentage of female } \\
\text { researchers among first } \\
\text { authors }(n=1136)\end{array}$ & $p$-Values & $\begin{array}{l}\text { Percentage of female } \\
\text { researchers among last } \\
\text { authors }(n=1136)\end{array}$ & $p$-Values \\
\hline Overall & $26.5 \%(23.9-29.2 \%)$ & & $25.3 \%(22.3-28.4 \%)$ & \\
\hline $\begin{array}{l}\text { Manuscripts published } \\
\text { in journals with } \\
\text { IF }<10(n=826)\end{array}$ & $25.3 \%(22.3-28.4 \%)$ & 0.246 & $22.3 \%(19.2-25.6 \%)$ & 0.696 \\
\hline $\begin{array}{l}\text { Manuscripts published } \\
\text { in journals with } \\
\text { IF } \geq 10(n=310)\end{array}$ & $29.7 \%(24.6-35.1 \%)$ & & $23.6 \%(17.7-30.3 \%)$ & \\
\hline $\begin{array}{l}\text { Manuscripts published } \\
\text { in North American } \\
\text { journals }(n=339)\end{array}$ & $25.7 \%(21.1-30.7 \%)$ & 0.487 & $24.4 \%(19.5-29.8 \%)$ & 0.060 \\
\hline $\begin{array}{l}\text { Manuscripts published } \\
\text { in European journals } \\
(n=619)\end{array}$ & $28.3 \%(24.7-31.9 \%)$ & & $23.1 \%(19.3-27.3 \%)$ & \\
\hline $\begin{array}{l}\text { Manuscripts published } \\
\text { in Asian journals } \\
(n=156)\end{array}$ & $23.1 \%(16.7-30.5 \%)$ & & $10.8 \%(6.1-17.5 \%)$ & \\
\hline $\begin{array}{l}\text { Manuscripts published } \\
\text { in Australian journals } \\
(n=10)\end{array}$ & $20.0 \%(2.5-55.6 \%)$ & & $75.0 \%(34.9-96.8 \%)$ & \\
\hline $\begin{array}{l}\text { Manuscripts published } \\
\text { in international } \\
\text { journals }(n=12)\end{array}$ & $8.3 \%(0.3-38.5 \%)$ & & $50.7 \%(18.4-90.1 \%)$ & \\
\hline
\end{tabular}

IF, impact factor. Data are expressed as percentages and $95 \%$ confidence intervals (in parentheses). $p$-Values were calculated by the chi-squared test
Indirectly, once again, these results may point out the existence of barriers to the scientific career progress of women. In fact, many obstacles might disincentivize women from a scientific career, including organizational constraints, sexual harassment, cultural prejudices, as well as specific work and family requests (namely, work-life balance) (Schwalbe and Fearon 2018; Mathad et al. 2019; Shannon et al. 2019).

Our study has some important limitations that should be mentioned. First, we were unable to obtain relevant information including age, ethnicity, h-index, and years spent working in science. Second, with respect to the initial selection, we had to exclude approximately $21 \%$ of the initial items because we were unable to find the gender of the first and/or last authors with certainty. Third, the time interval of our research was relatively short.

In conclusion, gender equality is vital because it is able to give health and benefits (Shannon et al. 2019). In fact, several studies have recently documented that, in science, gender equality improves innovation, productivity, quality, and satisfaction (Shannon et al. 2019). Our study reports that, also in this dramatic period, there is a gender gap in science. Therefore, gender equality is not only an obligation of governments and global health institutions (as correctly suggested by Wenham et al. 2020) but also a duty of the scientific community.

\section{Compliance with ethical standards}

Conflict of interest The authors have no potential conflicts of interest to disclose.

Ethical approval The local ethics committee approved the study protocol.

Informed consent The ethics committee exempted our research from the informed consent requirement.

\section{References}

Mathad JS, Reif LK, Seo G, Walsh KF, McNairy ML, Lee MH, Hokororo A, Kinikar A, Riche CT, Deschamps MM, Nerette S, Nimkar S, Kayange N, Jaka H, Joseph G, Morona D, Peter TY, Suryavanshi N, Fitzgerald DW, Downs JA (2019) Female global health leadership: data-driven approaches to close the gender gap. Lancet 393:521-523

Schwalbe N, Fearon J (2018) Time's up for journal gender bias. Lancet 391:2601-2602

Shannon G, Jansen M, Williams K, Caceres C, Motta A, Odhiambo A, Eleveld A, Mannell J (2019) Gender equality in science, medicine, and global health: where are we at and why does it matter? Lancet 393:560-569

Wenham C, Smith J, Morgan R; Gender and COVID-19 Working Group (2020) COVID-19: the gendered impacts of the outbreak. Lancet 395:846-848

Publisher's note Springer Nature remains neutral with regard to jurisdictional claims in published maps and institutional affiliations. 